\title{
The RNA polymerase of influenza A virus: mechanisms of viral transcription and replication
}

\author{
E. FODOR
}

Sir William Dunn School of Pathology, University of Oxford, South Parks Road, Oxford OX1 3RE, United Kingdom

\begin{abstract}
Summary. - The influenza A virus RNA genome segments are packaged in ribonucleoprotein complexes containing RNA polymerase and nucleoprotein. The ribonucleoprotein is involved in the transcription of viral genes and replication of the viral RNA genome in the nucleus of the infected cells, and represents the minimal transcriptional and replicative machinery of an influenza virus. During transcription, the viral RNA polymerase synthesizes capped and polyadenylated mRNA using 5' capped RNA primers. During replication, the viral RNA polymerase generates a complementary RNA (cRNA) replication intermediate, a full-length complement of the vRNA that serves as a template for the synthesis of new copies of vRNA. The nucleoprotein is also an essential component of the viral transcriptional machinery. The molecular determinants of the transcriptional and replicative activities of the viral RNA polymerase are not fully understood, but recent data suggest that transcription is performed by a cis-acting RNA polymerase, forming part of the ribonucleoprotein complex, while replication might be carried out by a trans-acting RNA polymerase. Viral as well as cellular factors are known to be involved in the regulation of the activities of the RNA polymerase, e.g. the viral nuclear export protein has been shown to regulate the accumulation of viral transcription and replication products. The viral transcriptional machinery represents an attractive target for the development of antiviral drugs and lead compounds targeting nucleoprotein and the PA endonuclease domain of the RNA polymerase have already been identified.
\end{abstract}

Keywords: influenza virus; RNA polymerase; nucleoprotein; transcription; replication

Contents:

1. Introduction

2. The viral replication cycle

3. The viral RNA polymerase and the nucleoprotein

4. Transcription of viral genes

4.1 Mechanisms of transcription initiation and polyadenylation

4.2 Mechanisms of mRNP assembly and nuclear export

5. Replication of the viral RNA genome

5.1 Mechanisms of replication: cis-acting versus trans-acting polymerase

5.2 Mechanisms of nuclear export of vRNPs

6. Conclusions

E-mail: ervin.fodor@path.ox.ac.uk; phone: +44-1865-275580.

Abbreviations: $\mathrm{Crm} 1=$ chromosome region maintenance 1 ; cRNA = complementary RNA; NEP = nuclear export protein; $\mathrm{NP}=$ nucleoprotein; $\mathrm{PA}=$ polymerase acidic protein; $\mathrm{PB} 1=$ polymerase basic protein $1 ; \mathrm{PB} 2=$ polymerase basic protein 2 ; $\mathrm{RNP}=$ ribonucleoprotein; vRNA = viral RNA

\section{Introduction}

Influenza viruses are important human pathogens that cause yearly epidemics and occasional pandemics. Vaccines against seasonal influenza are available but these are unlikely to protect against an emerging pandemic strain. Although efforts to develop a universal vaccine that would offer protection against all influenza A virus subtypes are underway, it remains to be seen to what extent such efforts will be successful (reviewed in Ekiert and Wilson (2012). In the absence of a universal vaccine, preparing sufficient quantities of a matching vaccine against an emerging pandemic virus can take several months and in such situations antivirals would represent the first line of defence. However, the number of available antivirals against influenza virus is limited to those targeting the viral M2 ion channel (amantadine and rimantadine) or neuraminidase (oseltamivir and zanamivir) and emerging antiviral resistance against these is a problem (reviewed in Das (2012). An alternative target for the development of antivirals is the viral transcriptional 
machinery consisting of the trimeric RNA-dependent RNA polymerase complex and of genomic RNA associated with the viral nucleoprotein (NP). Therefore considerable effort has been spent in recent years on studies aiming to obtain high resolution structural information of the transcriptional machinery and to understand the control mechanisms of transcription of viral genes and replication of the viral genome. This review focuses on recent findings on the influenza A virus RNA polymerase and the mechanisms that control the transcriptional and replicative activities of the RNA polymerase during the viral replication cycle.

\section{The viral replication cycle}

Influenza A virus belongs to the family of Orthomyxoviridae and contains eight segments of single stranded negative sense viral RNA (vRNA) as its genome (Palese and Shaw, 2007). These eight segments are reported to encode at least 16 polypeptides, some of which were only discovered in recent years, suggesting that our understanding of the influenza virus proteome might still be incomplete (Jagger et al., 2012; Muramoto et al., 2012; Wise et al., 2009; Wise et al., 2012). Within the virion the vRNA segments occur in the form of ribonucleoprotein complexes (vRNPs). More specifically, the highly conserved 5' and 3' termini of vRNA interact through base-pairing to form a partially double-stranded structure which is bound by the trimeric RNA-dependent RNA polymerase complex. The rest of the vRNA associates with multiple copies of oligomeric nucleoprotein (NP) with one NP for approximately every 24 nucleotides. A vRNA segment with bound RNA polymerase and nucleoprotein represents the minimal transcriptional and replicative machinery of an influenza virus. Viral infection initiates with the binding of the infecting virion to cell surface receptors containing sialic acid, followed by the endocytosis of the virion. After fusion of the viral and endosomal membranes the vRNPs are released into the cytoplasm and then transported into the nucleus. In the nucleus the viral RNA polymerase transcribes the vRNA segments into mRNAs, which are 5' capped and 3' polyadenylated. mRNA is exported to the cytoplasm for translation by cellular mechanisms. The viral RNA polymerase also performs replication of vRNA by copying it into complementary RNA (cRNA) which in turn serves as a template for the production of more vRNA. cRNA and vRNA are assembled with newly expressed viral polymerase and NP to form vRNPs and cRNPs, respectively. Following nuclear export, progeny vRNPs are transported across the cytoplasm in a Rab11- and microtubule-dependent manner to the cell membrane, where assembly of progeny virions takes place followed by their release by budding. The 5 ' and 3 ' termini of each segment, including the non-coding regions as well as parts of the coding regions, contain signals required for the specific packaging of each of the eight genome segments into virions (reviewed in Hutchinson et al. (2010)). However, the nature of these packaging signals and the mechanism how the eight segments are selected for remains unknown.

\section{The viral RNA polymerase and the nucleoprotein}

The trimeric viral RNA-dependent RNA polymerase, consisting of polymerase basic protein 1 (PB1), polymerase basic protein 2 (PB2) and polymerase acidic protein (PA) subunits, is responsible for the transcription and replication of the viral RNA genome segments. Biochemical studies indicated that the $\mathrm{C}$ terminus of $\mathrm{PA}$ interacts with the $\mathrm{N}$ terminus of $\mathrm{PB} 1$ and the $\mathrm{C}$ terminus of $\mathrm{PB} 1$ interacts with the $\mathrm{N}$ terminus of $\mathrm{PB} 2$, suggesting an $\mathrm{N}$-terminal to C-terminal linear PA-PB1-PB2 arrangement of the subunits, without apparent direct interaction between PA and PB2. However, three-dimensional images obtained by singleparticle analysis using electron microscopy indicate that the RNA polymerase forms a compact globular structure, suggesting more intimate interactions between all three subunits (Arranz et al., 2012; Coloma et al., 2009; Moeller et al., 2012). Indeed, a direct interaction between PA and PB2 was reported when a bimolecular fluorescence complementation assay was used to study their interaction (Hemerka et al., 2009). High-resolution structural studies confirmed the interaction domains between the PA and PB1 as well as between the PB1 and PB2 subunits (He et al., 2008; Obayashi et al., 2008; Sugiyama et al., 2009).

The PB1 subunit contains the conserved motifs characteristic of RNA-dependent RNA polymerases and catalyzes the sequential addition of nucleotides during RNA chain elongation. Although no structural information is available for the active site of PB1, sequence alignments and mutational analysis show that an S-D-D motif in the central region of $\mathrm{PB} 1$ is likely to form the active site (Biswas and Nayak, 1994). PB1 is also involved in binding to the terminal 5' and '3' sequences of vRNA and cRNA within the vRNP and cRNP, respectively (Gonzalez and Ortin, 1999; Li et al., 1998). The exact location of these sites has not been resolved, although the regions flanking the polymerase motifs are strongly implicated. The PA and PB2 subunits are likely to contribute to promoter binding as they can be photochemically cross-linked to promoter RNA, but the exact nature of these interactions remains to be determined (Fodor et al., 1993, 1994; Pritlove et al., 1995).

The PB2 and PA subunits play critical roles in the initiation of transcription by binding to and cleaving capped host pre-mRNAs, respectively. Although the cap binding site has been associated with various regions of $\mathrm{PB} 2$, structural analysis of the cap-binding domain in complex with $\mathrm{m}^{7} \mathrm{GTP}$ confirmed the involvement of two aromatic amino acid resi- 
dues, H357 and F404, which sandwich the methylated base in a manner similar to that described for other cap-binding proteins (eIF4E, CBP20, and vaccinia virus VP39) (Fechter and Brownlee, 2005; Fechter et al., 2003; Guilligay et al., 2008). The endonuclease domain, responsible for cleaving capped pre-mRNA, has been shown by structural analysis to reside in the N-terminal domain of the PA subunit, in agreement with previous mutagenic analyses (Dias et al., 2009; Hara et al., 2006; Yuan et al., 2009). The fold of the endonuclease domain and its biochemical properties are similar to those of type II restriction endonucleases and it involves the binding of the bivalent metal ions $\mathrm{Mn}^{2+}$ or $\mathrm{Mg}^{2+}$.

$\mathrm{NP}$ is essential for transcription of viral genes and replication of the viral RNA genome, and represents an important structural component of vRNPs and cRNPs. It is an RNA binding protein that binds RNA with high affinity but no sequence specificity (Yamanaka et al., 1990). The high-resolution atomic structures of H1N1 and H5N1 influenza A virus NPs have been solved in the form of a trimeric complex which revealed a structure consisting of a head domain, a body domain and a tail loop/linker region (Ng et al., 2008; Ye et al., 2006). Several clusters of basic amino acid residues have been identified which play a role in RNA binding. In addition to RNA binding, NP can also homo-oligomerize through the tail loop of one NP molecule being inserted into a groove in the body domain of a neighbouring NP molecule (Chan et al., 2010). The identification of phosphorylation sites in the tail loop and groove of NP suggests that NP oligomerisation might be regulated by phosphorylation (Hutchinson et al., 2012). Functional analyses indicate that homo-oligomerization as well as RNA-binding are important properties of NP as oligomerisation and RNA binding mutants cannot support the transcription and replication of genome-length vRNA templates (Chan et al., 2010). NP is also known to interact with the PB1 and PB2 subunits of the RNA polymerase (Biswas et al., 1998; Poole et al., 2004). Three amino acid residues in a loop at the top of the head domain of NP were found to be required for both its binding to the viral polymerase and its ability to support viral RNA synthesis catalyzed by the viral polymerase (Marklund et al., 2012).

Recent studies using cryo-electron microscopy revealed a double-helical arrangement of the influenza virus RNP resembling a large loop twisted into a helical filament with the RNA polymerase at one end and a short loop at the other end (Arranz et al., 2012; Moeller et al., 2012). Within this helical filament, the anti-parallel NP-RNA strands were found to associate with each other, exhibiting a major and a minor groove similar to a DNA duplex. However, unlike in DNA, the interactions between the anti-parallel NP-RNA strands appear to be solely mediated by the NP molecules rather than nucleotide pairing. Interactions between adjacent
NP molecules on the same RNA strand are facilitated by the tail loop-groove interaction.

The influenza virus genome is of negative sense and therefore the RNA polymerase must be packaged into virus particles and introduced into infected cell nuclei as part of the vRNPs to allow an initial round of transcription early during infection. In addition, during the viral life cycle new RNA polymerase and NP are produced, which must be transported into the nucleus to allow assembly of cRNPs and progeny vRNPs as well as to carry out transcription and replication. Various models have been proposed to explain how the RNA polymerase is imported into the nucleus and assembled into a trimeric complex (reviewed in Hutchinson and Fodor (2012)). However, most studies agree that PB1 and PA form a dimeric complex in the cytoplasm which is imported into the nucleus by Ran binding protein 5 (RanBP5), a member of the importin $\beta$ family of cellular import factors, shown to associate with PB1 (Deng et al., 2006a; Hutchinson et al., 2011). In contrast, PB2 is imported separately by the classical importin $\alpha / \beta$ pathway and joins the PB1-PA dimer in the nucleus. Similarly to PB2, NP is also imported by the importin $\alpha / \beta$ pathway (Gabriel et al., 2008; O'Neill et al., 1995). Nuclear import and assembly could be further facilitated by interactions of the viral RNA polymerase and NP with cellular chaperones, i.e. Hsp90 and the CCT complex (Fislova et al., 2010; Naito et al., 2007). The nuclear import of PB2 and NP of avian and mammalian adapted influenza viruses depends on different importin $a$ isoforms and adaptive mutations have been identified that facilitate their nuclear import upon crossing species barriers (Gabriel et al., 2011). Thus the nuclear membrane may represent a species-specific barrier that needs to be overcome by mutations upon transmission of influenza viruses from one host to another in a manner analogous to the adaptation of avian influenza virus haemagglutinins to the a2,6-linked sialic acid receptors characteristic of human cells (reviewed in Resa-Infante and Gabriel (2012)).

\section{Transcription of the viral genes}

\subsection{Mechanisms of transcription initiation and polyade-} nylation

Viral mRNA synthesis is initiated by a cis-acting viral RNA polymerase that is part of the vRNP structure and is bound to the vRNA promoter formed by the terminal $5^{\prime}$ and 3 ' sequences of the vRNA template (Fig. 1) (Fodor et al., 1994; Hagen et al., 1994; Luytjes et al., 1989). The vRNA contains 13 nucleotides at the $5^{\prime}$ end, and 12 nucleotides at the 3 ' end, which are conserved between all eight segments in all influenza A viruses, and display partial inverted complementarity (Desselberger et al., 1980). These ends were 
found to interact both in infected cells and virions (Hsu et al., 1987). Based on NMR analysis of short synthetic RNAs, extensive mutagenic analysis using in vitro transcription of synthetic templates, and reporter gene analysis in vivo, several secondary structures have been proposed for the vRNA promoter (reviewed in (Neumann et al., 2004)). The currently favoured model, based on functional analysis, is the corkscrew model which predicts an internal stretch of a based-paired region, consisting of 5-7 base pairs depending on the segment, with the very ends adopting two-base-pair hairpin loop conformations (Flick et al., 1996). These hairpin loop structures have been shown to be required for binding the RNA polymerase complex.

Viral mRNA synthesis depends on cellular RNA polymerase II (Pol II) activity as it requires a 5' capped RNA primer which is derived from host pre-mRNAs. Indeed, inhibitors of Pol II, e.g. alpha-amanitin, were found to specifically inhibit viral transcription (Chan et al., 2006; Mark et al., 1979). The capped primer is generated by the viral RNA polymerase, with the $\mathrm{PB} 2$ subunit involved in binding to the 5 ' cap of a pre-mRNA through its cap-binding domain, and the PA subunit responsible for its endonucleolytic cleavage (Fig. 1) (Dias et al., 2009; Guilligay et al., 2008; Yuan et al., 2009). The viral polymerase was found to associate with Pol II and this association might facilitate the access of the viral polymerase to the $5^{\prime}$ cap of host nascent pre-mRNAs (Engelhardt et al., 2005). To carry out cap-binding and endonuclease cleavage, the RNA polymerase also needs to be associated with the vRNA template (Hagen et al., 1994). Cleavage of host pre-mRNAs occurs at a site approximately 10-13 nucleotides downstream of the cap structure, resulting in primers with a $3^{\prime}$-hydroxyl group. Transcription is usually initiated by the addition of a $G$ residue to the 3 ' end of the capped primer, directed by the penultimate $\mathrm{C}$ residue at the 3 ' end of the vRNA template. However, initiation by the addition of a $\mathrm{C}$ residue directed by the $\mathrm{G}$ residue at position 3 in the vRNA template has also been observed. The presence of a cap-1 structure with a 7-methyl on the terminal G as well as a 2 '-O-methyl on the penultimate base of the primer strongly increase priming activity (Bouloy et al., 1980). There seems to be a preference for primers with " $\mathrm{CA}^{\prime}$ " 3 ' ends to be used for transcription initiation in infected cells (Beaton and Krug, 1981; Shaw and Lamb, 1984) although the structural basis for this sequence specificity remains unknown.

Transcription elongation proceeds until a sequence of 5-7 U residues usually located 16 nucleotides from the 5 ' end of the vRNA template (Fig. 1). This sequence of $U$ residues then acts as a signal for polyadenylation (Robertson et al., 1981). Unlike polyadenylation of host mRNAs which is carried out by a specific poly(A) polymerase, polyadenylation of viral mRNAs is catalyzed by the viral RNA polymerase. The viral polymerase is proposed to remain associated with the $5^{\prime}$ end of the vRNA template throughout elongation while the tem- plate is threaded through its active site in a $3^{\prime}$ to $5^{\prime}$ direction (Fig. 1) (Fodor et al., 1994; Hagen et al., 1994; Moeller et al., 2012). Upon the $U$ sequence reaching the active site of the polymerase, the template cannot proceed further because of steric hindrance caused by the $5^{\prime}$ end being bound to the polymerase. This will lead to template slipping and repeated copying of the $U$ sequence by the polymerase resulting in a poly(A) tail. In support of this model, mutations in the 5 ' end of vRNA template that affect polymerase binding were found to also affect polyadenylation (Poon et al., 1998). That the $\mathrm{U}$ sequence acts as a template for polyadenylation was proven by replacing the $U$ sequence with an $A$ sequence which resulted in mRNA transcripts with poly(U) tails. These were retained in the nucleus of infected cells, consistent with the poly(A) tail being required for the nuclear export of mRNAs (Poon et al., 1999, 2000).

In contrast to genome replication which continues late in infection, viral mRNA synthesis peaks early, at about 2-6 hours post-infection, after which it declines sharply (Shapiro et al., 1987; Vreede et al., 2010). This could be caused by the cell running out of cap-donor host mRNAs due to host shutoff and/or inhibition and degradation of Pol II induced by viral infection (reviewed in Vreede and Fodor (2010).

\subsection{Mechanisms of $m R N P$ assembly and nuclear export}

Cellular mRNA synthesis is believed to be coupled to RNA processing, including capping, splicing and polyadenylation, as well as assembly into mRNPs and their nuclear export (reviewed in Moore and Proudfoot (2009)). In an analogous manner, it is likely that viral transcription, mRNP assembly and nuclear export are closely linked processes, although the molecular details remain poorly characterized. After initiation of viral mRNA transcription the 5 ' cap of the nascent viral transcript is believed to be released from the PB2 subunit of the transcribing RNA polymerase and is likely to be bound by the $20 \mathrm{kDa}$ subunit of the nuclear cap binding complex (CBC) to initiate the assembly of viral mRNPs by the recruitment of further cellular factors, i.e. the TREX complex and NXF1/TAP, to ensure nuclear export (Fig. 1) (Bier et al., 2011; Braam et al., 1983; Read and Digard, 2010; Wang et al., 2008). The association of the viral RNA polymerase with the cellular Pol II transcriptional machinery might not only facilitate the access of the viral RNA polymerase to the 5 ' cap structure of nascent host pre-mRNAs, but might also participate in the recruitment of the these mRNA nuclear export factors as well as the splicing machinery to viral mRNAs. Two genome segments, segments 7 and 8 , give rise to mRNAs that can undergo splicing with both the unspliced and the spliced versions being translated (Lamb and Choppin, 1979; Lamb et al., 1980). Segment 7 unspliced mRNA encodes the matrix protein 1 (M1). Three spliced versions of segment 7 mRNA are known, one of which encodes the M2 ion channel. 


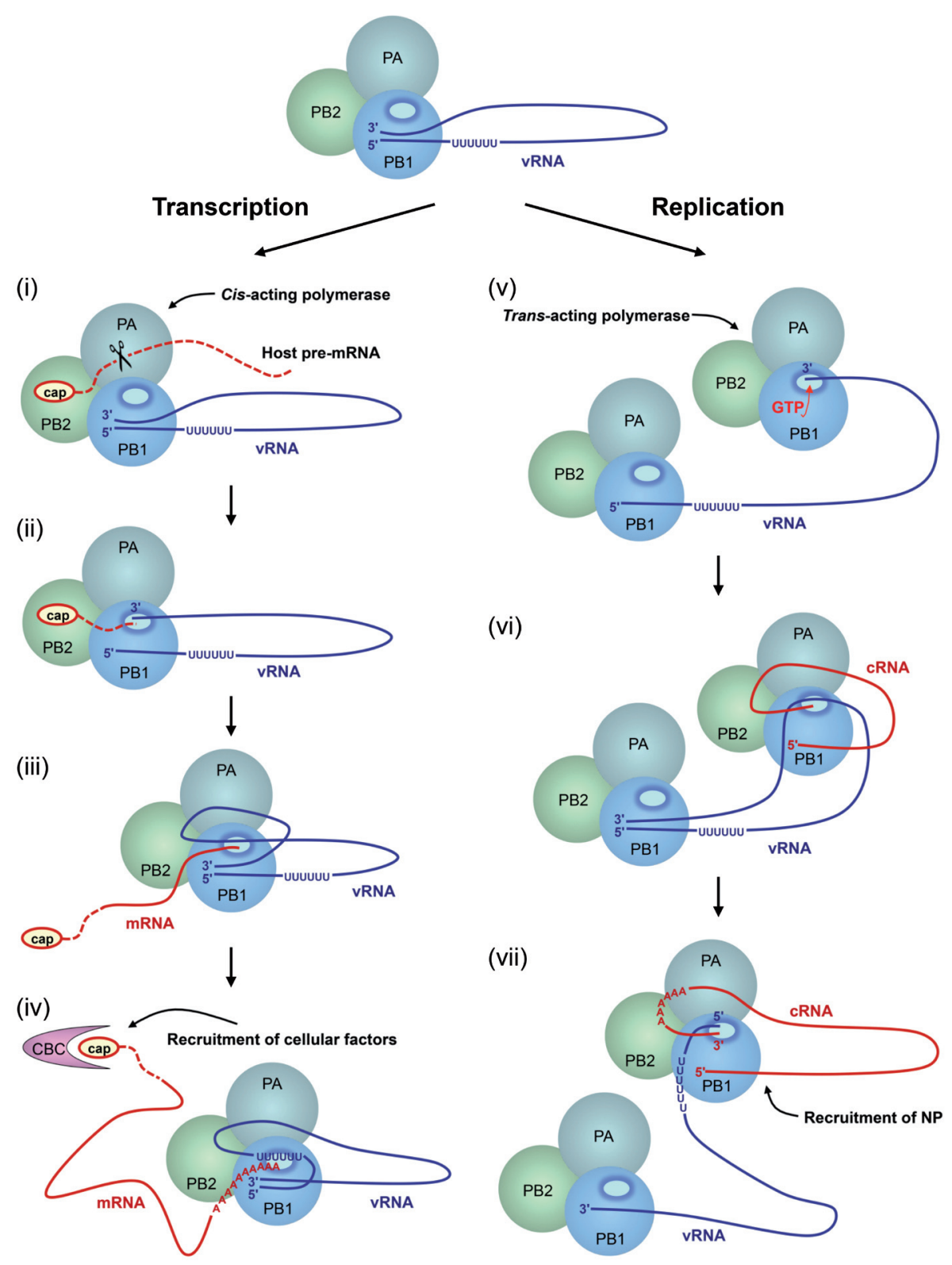

Fig. 1

Models for the transcription and replication of the influenza virus vRNP

In a vRNP the viral polymerase, consisting of the PB1, PB2 and PA subunits, is bound to the partially complementary 5 ' and $3^{\prime}$ termini of a vRNA segment. The oligomeric nucleoprotein that associates with the rest of the vRNA is not shown for simplicity. (i) Transcription is initiated by PB2 binding to the 5 ' cap structure of host pre-mRNA followed by endonucleolytic cleavage of the host pre-mRNA by PA. (ii) The 3' end of the capped RNA primer is positioned in the active site of PB1, along with the $3^{\prime}$ end of the vRNA template, to allow transcription initiation to take place. (iii) Once the 3 ' end of vRNA has been copied it re-binds the polymerase, a process possibly facilitated by base-pairing between the vRNA termini. (iv) As elongation proceeds the vRNA template is threaded through the active site of PB1 eventually leading to polyadenylation by repeated copying of the U sequence near the 5 ' end of the vRNA template, due to steric hindrance caused by the vRNA 5' end remaining bound to the transcribing polymerase. The 5' cap of mRNA is released from PB2 and is bound by the cellular nuclear cap-binding complex (CBC) triggering the recruitment of cellular factors for mRNP assembly. (v) Replication of vRNA into cRNA is shown as proposed in the trans-acting polymerase model, but note that alternative models involving a cis-acting polymerase in vRNA $\rightarrow$ cRNA replication have also been proposed (see text for details). According to the trans-acting polymerase model, the 3' end of the vRNA template is released from the vRNP-associated polymerase by an unknown mechanism that allows it to bind to a trans-acting RNA polymerase. Replication is initiated by the binding of the trans-acting polymerase to GTP, directed by the penultimate residue in the vRNA 3 ' terminus, and the generation of pppApG (not shown) to be elongated by the transacting polymerase. (vi) Once the $3^{\prime}$ end of vRNA has been copied it re-binds the vRNP-associated polymerase while the $5^{\prime}$ end of the newly synthesized cRNA binds to the trans-acting polymerase. (vii) As elongation proceeds the 5 ' end of vRNA template needs to be released by the vRNA-associated polymerase to allow the trans-acting polymerase to read through the U sequence near the 5 ' end of vRNA to generate a full-length, run-off copy of vRNA. After the 5 ' end of vRNA has been copied it re-binds the vRNP-associated polymerase while the $3^{\prime}$ end of the newly synthesized cRNA binds to the trans-acting polymerase which becomes part of the cRNP complex. Co-replicational encapsidation of cRNA with NP is not shown for simplicity. 
Another spliced mRNA, in certain influenza virus strains, encodes a variant form of M2 called M42 (Wise et al., 2012). Segment 8 unspliced mRNA is translated into non-structural protein 1 (NS1) which has an interferon antagonist function, while the spliced version is translated into the nuclear export protein NEP (also known as non-structural protein 2 (NS2)). For splicing, influenza virus relies entirely on the host cell splicing machinery, although viral factors could play a regulatory role (Garaigorta and Ortin, 2007; Robb et al., 2010). In particular, NS1 was shown to play a regulatory role in determining the ratios of alternatively spliced mRNA products from the M1 mRNA (Robb and Fodor, 2012). Thus influenza viruses use intronless mRNAs as well as spliced and unspliced versions of intron-containing mRNAs for protein translation. These different types of mRNAs most likely require a different set of cellular factors to produce nuclear export and translation competent mRNPs. Indeed, some aspects of mRNA assembly and nuclear export appear to be genome segment specific as viral mRNAs derived from different segments show differential dependence on cellular NXF1/TAP for their nuclear export (Read and Digard, 2010). After nuclear export, $\mathrm{CBC}$ is likely to be replaced in the cytoplasm by the eIF4E translation initiation factor (Bier et al., 2011), although it has also been reported that translation of viral mRNAs can proceed normally in different situations of functional impairment of the eIF4E factor suggesting that eIF4E might not be essential for the translation of influenza virus mRNAs (Burgui et al., 2007).

\section{Replication of the viral RNA genome}

\subsection{Mechanisms of replication: cis-acting versus trans-} acting polymerase

Replication of the viral RNA genome consists of two stages. During the first stage, genomic vRNA is replicated into $c$ RNA (vRNA $\rightarrow$ cRNA) (Fig. 1), while during the second stage the cRNA is copied into vRNA (cRNA $\rightarrow$ vRNA). cRNA represents a full-length copy of the vRNA, without a 5' cap structure and a 3' poly(A) tail, and therefore its synthesis requires initiation and termination mechanisms that are distinct from those used for the production of mRNA from the same vRNA template. Both cRNA and vRNA contain a 5' triphosphate strongly suggesting that their synthesis is initiated de novo in a primer-independent manner. For the vRNA promoter, primer-independent initiation occurs at the 3 ' terminus of vRNA. It has been proposed that the polymerase initially binds GTP, directed by the 3 '-terminal penultimate $\mathrm{C}$ residue in vRNA, followed by phosphodiester bond formation with ATP directed by template position 1, giving initially rise to the pppApG dinucleotide, which is then elongated by the polymerase (Vreede et al., 2008). Alter- natively, it has been suggested that initiation from the vRNA promoter is directed by the second residue of the $3^{\prime}$ end after the addition of a non-templated residue (preferentially a purine) to the 3 ' end of the vRNA template by host-specific ribonucleotidyltransferase (Zhang et al., 2010). For the cRNA promoter, pppApG is synthesized internally, directed by positions 4 and 5 of the $3^{\prime}$ end of cRNA, which then realigns to the 3 ' terminal residues 1 and 2 for subsequent elongation (Deng et al., 2006b). cRNA, being an exact copy of vRNA, also contains conserved 5' and 3' nucleotides which have the potential to form a partially double-stranded structure. Indeed, functional analysis strongly suggests that the cRNA promoter consists of both termini forming a similar, but not identical structure to that formed by the vRNA (Azzeh et al., 2001; Crow et al., 2004). Differences in vRNA and cRNA promoter structures could influence their binding properties to the RNA polymerase, thereby altering the site of initiation of pppApG synthesis. Proof of these mechanisms must await the crystallization and X-ray analysis of the influenza virus polymerase in complex with promoter RNAs.

The vRNPs introduced into the cell by the infecting virions must act as templates for both mRNA and cRNA synthesis (Fig. 1). A large body of research has been devoted to the question of what determines whether the vRNP is transcribed into mRNA or replicated into cRNA. Various models to explain the control mechanisms have been proposed which involve regulatory roles for viral factors (NP, RNA polymerase, NS1, NEP/NS2, small viral RNAs (svRNAs)) as well as host factors (e.g. MCM, UAP65, tatSF1 and the availability of capped RNA primers and rNTPs) (reviewed in Resa-Infante et al. (2011)). A model that mRNA synthesis is performed in cis by the RNA polymerase that forms part of the vRNP, while replication is performed in trans by an RNA polymerase that is distinct from the RNP-associated polymerase, has gained strong support in recent years (Fig. 1) (Jorba et al., 2009; Moeller et al., 2012). According to this model, newly synthesized RNA polymerase, distinct from the polymerase in vRNPs introduced into cells by the infecting virions, would be required for replication and the incoming vRNP would simply act as a template for a second, trans-acting polymerase. In this model, the 3' end of the vRNA template needs to be released by the vRNP-associated polymerase to be copied by the trans-acting polymerase into the $5^{\prime}$ end of the new cRNA which then binds to the replicating trans-acting polymerase (Fig. 1). After 5 ' terminus binding, the first NP is added to the product cRNA adjacent to the replicating polymerase, initiating encapsidation of cRNA in a $5^{\prime}$ to $3^{\prime}$ direction (Moeller et al., 2012). Thus, encapsidation of cRNA would be triggered by the sequence specific binding of the trans-acting RNA polymerase to the cRNA 5 ' terminus. The binding of NP to nascent viral RNA may be facilitated by UAP56 and Tat-SF1, proposed to act as chaperones for NP (Momose et 
al., 2001; Naito et al., 2007a). A similar mechanism would also operate during the replication of cRNPs into vRNPs. In support of this replication model, recent examination of negative stain EM micrographs revealed RNP complexes with a branched arrangement in which a smaller nascent RNP appears to bud from a larger full-length RNP (Moeller et al., 2012). Additionally, a polymerase residing at the junction of the smaller RNA with the full-length RNP was observed, in agreement with replication being carried out by a trans-acting polymerase.

The proposed model of replication being carried out by a trans-acting RNA polymerase is in agreement with previous observations that viral protein synthesis is required for RNA genome replication, and that in the presence of the translation inhibitor cycloheximide only mRNA can be detected in infected cells (Mark et al., 1979; Vreede et al., 2004). Although this observation originally led to the hypothesis that a viral protein is required to switch the activity of the incoming vRNPs from transcription into replication mode with biochemical studies strongly suggesting the NP might perform this function, emerging evidence suggests that NP plays no regulatory role in determining the mode of initiation and termination by the viral RNA polymerase. In particular, short genome segments (up to $76 \mathrm{nt}$ ) with large internal deletions but preserving the $5^{\prime}$ and $3^{\prime}$ terminal sequences were found to be efficiently transcribed and replicated in the absence of NP in vivo, resulting in authentic 5' capped and 3' polyadenylated mRNA-like transcripts and non-capped nonpolyadenylated vRNA- and cRNA-like replication products (Resa-Infante et al., 2010; Turrell et al., 2013). It is therefore more likely that the main reason for viral protein synthesis being required for genome replication is to provide newly synthesized trans-acting RNA polymerase and newly synthesized NP to co-replicationally encapsidate and stabilize full-length replication products.

The proposal of the model that transcription is performed by a cis-acting polymerase while replication is carried out by a trans-acting polymerase is an important step towards understanding the molecular mechanisms of influenza virus transcription and genome replication. However, a lot of questions remain unanswered. For example, it is not clear how the release of the vRNA $3^{\prime}$ end from the vRNPassociated polymerase would be triggered to allow a transacting polymerase to bind to it and use it as template to initiate replication. Moreover, the model that the first step of replication (vRNA $\rightarrow$ cRNA) is carried out by a trans-acting polymerase is not fully compatible with the observation that vRNPs isolated from virions can produce cRNA in vitro and vRNPs introduced into the cell by infecting virions have the capability to produce both mRNA and cRNA early on during infection (Vreede and Brownlee, 2007; Vreede et al., 2004). It was suggested that although cRNA is synthesized early it is quickly degraded by cellular nucleases in the absence of newly synthesized viral RNA polymerase and NP. However, cRNA can be detected if RNA polymerase and NP are preexpressed to stabilize it and, significantly, cRNA can also accumulate in the presence of a mutant RNA polymerase that can bind cRNA but cannot replicate, strongly suggesting that cRNA synthesis can be performed by vRNP-associated RNA polymerase. This led to the proposal that a trans-acting polymerase might operate on the cRNP, but not on the vRNP template (Jorba et al., 2009). Alternatively, early low levels of replication of vRNA into cRNA might be directed by a cisacting polymerase but once newly synthesized polymerase accumulates in the nucleus, most replication would be transacting polymerase dependent. Further studies are needed to address the significance of a trans-acting polymerase in the two stages of replication.

It has been proposed the viral NEP is involved in the regulation of viral RNA synthesis. In particular, NEP was found to up-regulate the accumulation of replication products while down-regulating the accumulation of transcription products in RNP expression assays in vivo (Robb et al., 2009). The involvement of NEP in the regulation of viral RNA synthesis gained further support recently when it was found that adaptive mutations in NEP can compensate for defective replication by partially or non-adapted RNA polymerase from an $\mathrm{H} 5 \mathrm{~N} 1$ avian influenza virus in mammalian cells, possibly by directly interacting with the RNA polymerase (Manz et al., 2012). Another study suggested that NEP could regulate viral RNA synthesis by promoting the synthesis of small viral RNAs (svRNAs) (Perez et al., 2010). svRNAs 22$27 \mathrm{nt}$ in length, corresponding to the 5' end of each of the vRNA segments, were found to be expressed at high levels in infected cells (Perez et al., 2010; Umbach et al., 2010). Their expression correlates with the accumulation of vRNA and a bias in RNA polymerase activity from transcription towards genome replication. Consequently, it was proposed that svRNA promotes replication, possibly through an interaction with a novel RNA binding channel of the polymerase PA subunit (Perez et al., 2012). It is plausible that svRNAs might promote the second stage of replication (cRNA $\rightarrow$ vRNA) by associating with trans-acting RNA polymerase.

\subsection{Mechanisms of nuclear export of $v R N P s$}

Progeny vRNPs are exported from the nucleus by the Crm1 pathway. In particular, the viral NEP mediates the nuclear export of vRNPs by directly interacting with Crm 1 (reviewed in (Paterson and Fodor, 2012)). NEP interacts with vRNPs through the viral matrix protein $\mathrm{M} 1$ which is believed to bind NP, although it also has direct RNA-binding activity (Akarsu et al., 2003; Wakefield and Brownlee, 1989). However, more recently an interaction between NEP and the viral RNA polymerase has also been demonstrated (Manz et al., 2012) raising the possibility that NEP could 
also mediate nuclear export of vRNPs through an interaction with the RNA polymerase. Moreover, nuclear export mediated directly by NP cannot be excluded (Elton et al., 2001). It appears that vRNPs are selectively exported, while cRNPs are restricted to the nucleus. The molecular basis of this selectivity is not fully understood, although it has been linked to the differences in the promoter structures of vRNA and cRNA (Tchatalbachev et al., 2001). It was proposed recently that vRNP complexes gain preferential access to cellular export machinery through chromatin targeting (Chase et al., 2011). In particular, chromatin targeting of vRNP export complexes brings them into association with Rccl, the Ran guanine exchange factor responsible for generating RanGTP and driving Crm1dependent nuclear export.

\section{Conclusions}

The influenza virus transcriptional machinery is a potential target for the development of antiviral drugs and the recent developments in our understanding of the molecular structures of the RNA polymerase and NP, and of their interplay during the processes of viral transcription and replication, will without any doubt greatly facilitate the development of novel classes of influenza antivirals. In particular, the endonuclease active site in the $\mathrm{N}$-terminal region of the PA appears to be an excellent target for the development of antiviral drugs and crystallographic studies have facilitated this approach (Dias et al., 2009; Yuan et al., 2009). Recently two groups reported structures of complexes of the PA endonuclease with several compounds that are known or were predicted to inhibit endonuclease-dependent polymerase activity (DuBois et al., 2012; Kowalinski et al., 2012), revealing new strategies for structure-based design and optimization of PA endonuclease inhibitors. Apart from the endonuclease domain of the RNA polymerase, other domains, e.g. the cap-binding domain of the PB2 subunit, the interaction domains between the three subunits, as well as the nucleoprotein provide alternative targets for drug development (reviewed in Das (2012)).

Acknowledgement. E.F. is grateful to Edward Hutchinson and Frank Vreede for critical reading of the manuscript. Research in E.F.'s laboratory is supported by the MRC and BBSRC.

\section{References}

Akarsu H, Burmeister W P, Petosa C, Petit I, Muller CW, Ruigrok RW, Baudin F, EMBO J. 22, 4646-4655, 2003. http://dx.doi. org/10.1093/emboj/cdg449
Arranz R, Coloma R, Chichon FJ, Conesa JJ, Carrascosa JL, Valpuesta JM, Ortin J, Martin-Benito J, Science 338, 1634-1637, 2012.

Azzeh M, Flick R, Hobom G, Virology 289, 400-410, 2001. http:// dx.doi.org/10.1006/viro.2001.1107

Beaton AR, Krug,RM, Nucleic Acids Res. 9, 4423-4436, 1981. http:// dx.doi.org/10.1093/nar/9.17.4423

Bier K, York A, Fodor E, J. Gen. Virol. 92, 1627-1634, 2011.

Biswas SK, Boutz PL, Nayak DP, J. Virol. 72, 5493-54501, 1988.

Biswas SK, Nayak DP, J. Virol. 68, 1819-1826, 1994.

Bouloy M, Plotch SJ, Krug RM, Proc. Natl. Acad. Sci. USA 77, 39523956, 1980. http://dx.doi.org/10.1073/pnas.77.7.3952

Braam J, Ulmanen I, Krug RM, Cell 34, 609-618, 1983.

Burgui I, Yanguez E, Sonenberg N, Nieto A, J. Virol. 81, 12427 12438, 2007. http://dx.doi.org/10.1128/JVI.01105-07

Chan AY, Vreede FT, Smith M, Engelhardt OG, Fodor E, 351, 210-217, 2006

Chan WH., Ng AK, Robb NC, Lam MK, Chan PK, Au SW, Wang JH, Fodor E, Shaw PC, J. Virol. 84, 7337-7345, 2010. http://dx.doi.org/10.1128/JVI.02474-09

Chase GP, Rameix-Welti MA, Zvirbliene A, Zvirblis G, Gotz V, Wolff T, Naffakh N, Schwemmle M, PLoS Pathog 7, e1002187, 2011. http://dx.doi.org/10.1371/journal.ppat.1002187

Coloma R, Valpuesta JM, Arranz R, Carrascosa JL, Ortin J, MartinBenito J, PLoS Pathog 5, e1000491, 2009. http://dx.doi. org/10.1371/journal.ppat.1000491

Crow M, Deng T, Addley M, Brownlee GG, J. Virol. 78, 6263-6270, 2004. http://dx.doi.org/10.1128/JVI.78.12.6263-6270.2004

Das K, J. Med. Chem. 55, 6263-6277, 2012. http://dx.doi. org/10.1021/jm300455c

Deng T, Engelhardt OG, Thomas B, Akoulitchev AV, Brownlee GG, Fodor E, J. Virol. 80, 11911-11919, 2006a. http://dx.doi. org/10.1128/JVI.01565-06

Deng T, Vreede FT, Brownlee GG, J. Virol. 80, 2337-2348, 2006b. http://dx.doi.org/10.1128/JVI.80.5.2337-2348.2006

Desselberger U, Racaniello VR, Zazra JJ, Palese P, Gene 8, 315-328, 1980. http://dx.doi.org/10.1016/0378-1119(80)90007-4

Dias A, Bouvier D, Crepin T, McCarthy AA, Hart DJ, Baudin F, Cusack S, Ruigrok RW, Nature 458, 914-918, 2009. http:// dx.doi.org/10.1038/nature07745

DuBois RM, Slavish PJ, Baughman BM, Yun MK, Bao J, Webby RJ, Webb TR, White SW, PLoS Pathog 8, e1002830, 2012. http://dx.doi.org/10.1371/journal.ppat.1002830

Ekiert DC, Wilson IA, Curr. Opin. Virol. 2, 134-141, 2012. http:// dx.doi.org/10.1016/j.coviro.2012.02.005

Elton D, Simpson-Holley M, Archer K, Medcalf L, Hallam R, McCauley J, Digard P, J. Virol. 75, 408-419, 2001. http:// dx.doi.org/10.1128/JVI.75.1.408-419.2001

Engelhardt OG, Smith M, Fodor E, J. Virol. 79, 5812-5818, 2005. http://dx.doi.org/10.1128/JVI.79.9.5812-5818.2005

Fechter P, Brownlee GG, J. Gen. Virol. 86, 1239-1249, 2005. http:// dx.doi.org/10.1099/vir.0.80755-0

Fechter P, Mingay L, Sharps J, Chambers A, Fodor E, Brownlee GG, J. Biol. Chem. 278, 20381-20388, 2003. http://dx.doi. org/10.1074/jbc.M300130200

Fislova T, Thomas B, Graef KM, Fodor E, J. Virol. 84, 8691-8699, 2010. http://dx.doi.org/10.1128/JVI.00813-10 
Flick R, Neumann G, Hoffmann E, Neumeier E, Hobom G, RNA 2, 1046-1057, 1996.

Fodor E, Pritlove DC, Brownlee GG, J. Virol. 68, 4092-4096, 1994.

Fodor E, Seong BL, Brownlee GG, J. Gen. Virol. 74, 1327-1333, 1993. http://dx.doi.org/10.1099/0022-1317-74-7-1327

Gabriel G, Herwig A, Klenk HD, PLoS Pathog 4, e11, 2008. http:// dx.doi.org/10.1371/journal.ppat.0040011

Gabriel G, Klingel K, Otte A, Thiele S, Hudjetz B, Arman-Kalcek G, Sauter M, Shmidt T, Rother F, Baumgarte S, Keiner B, Hartmann E, Bader M, Brownlee GG, Fodor E, Klenk HD, Nat. Commun. 2, 156, 2011. http://dx.doi.org/10.1038/ ncomms 1158

Garaigorta U, Ortin J, Nucleic Acids Res. 35, 4573-4782, 2007. http://dx.doi.org/10.1093/nar/gkm230

Gonzalez S, Ortin J, EMBO J. 18, 3767-3775, 1999. http://dx.doi. org/10.1093/emboj/18.13.3767

Guilligay D, Tarendeau F, Resa-Infante P, Coloma R, Crepin T, Sehr P, Lewis J, Ruigrok RW, Ortin J, Hart DJ, Cusack S, Nat. Struct. Mol. Biol. 15, 500-506, 2008. http://dx.doi. org/10.1038/nsmb.1421

Hagen M, Chung TD, Butcher JA, Krystal M, J. Virol. 68, 1509-1515, 1994.

Hara K, Schmidt FI, Crow M, Brownlee GG, J. Virol. 80, 7789-7798, 2006. http://dx.doi.org/10.1128/JVI.00600-06

He X, Zhou J, Bartlam M, Zhang R, Ma J, Lou Z, Li X, Li J, Joachimiak A, Zeng Z, Ge R, Rao Z, Liu Y, Nature 454, 1123-1126, 2008. http://dx.doi.org/10.1038/nature07120

Hemerka JN, Wang D, Weng Y, Lu W, Kaushik RS, Jin J, Harmon,AF, Li F, J. Virol. 83, 3944-3955, 2009. http://dx.doi. org/10.1128/JVI.02300-08

Hsu MT, Parvin JD, Gupta S, Krystal M, Palese P, Proc. Natl. Acad. Sci. USA 84, 8140-8144, 1987. http://dx.doi.org/10.1073/ pnas. 84.22 .8140

Hutchinson EC, Denham EM, Thomas B, Trudgian DC, Hester SS, Ridlova G, York A, Turrell L, Fodor E, PLoS Pathog. 8, e1002993. 2012. http://dx.doi.org/10.1371/journal. ppat. 1002993

Hutchinson EC, Fodor E, Vaccine 30, 7353-7358, 2012.

Hutchinson EC, Orr OE, Man Liu S, Engelhardt OG, Fodor E, J. Gen. Virol. 92, 1859-1869, 2011. http://dx.doi. org/10.1099/vir.0.032813-0

Hutchinson EC, von Kirchbach JC, Gog JR, Digard P, J. Gen. Virol. 91, 313-328, 2010. http://dx.doi.org/10.1099/ vir.0.017608-0

Jagger BW, Wise HM, Kash JC, Walters KA, Wills NM, Xiao YL, Dunfee RL, Schwartzman LM, Ozinsky A, Bell GL, Dalton RM, Lo A, Efstathiou S, Atkins JF, Firth AE, Taubenberger JK, Digard P, Science 337, 199-204, 2012. http://dx.doi. org/10.1126/science.1222213

Jorba N, Coloma R, Ortin J, PLoS Pathog. 5, e1000462, 2009. http:// dx.doi.org/10.1371/journal.ppat.1000462

Kowalinski E, Zubieta C, Wolkerstorfer A, Szolar OH, Ruigrok RW, Cusack S, PLoS Pathog. 8, e1002831, 2012. http://dx.doi. org/10.1371/journal.ppat.1002831

Lamb RA, Choppin PW, Proc. Natl. Acad. Sci. USA 76, 4908-4912, 1979. http://dx.doi.org/10.1073/pnas.76.10.4908
Lamb RA, Choppin PW, Chanock RM, Lai CJ, Proc. Natl. Acad. Sci. USA 77, 1857-1861, 1980. http://dx.doi.org/10.1073/ pnas.77.4.1857

Li ML, Ramirez BC, Krug RM, EMBO J. 17, 5844-5582, 1998. http:// dx.doi.org/10.1093/emboj/17.19.5844

Luytjes W, Krystal M, Enami M, Parvin JD, Palese P, Cell 59, 1107-1113, 1989. http://dx.doi.org/10.1016/0092$\underline{8674(89) 90766-6}$

Manz B, Brunotte L, Reuther P, Schwemmle M, Nat. Commun. 3, 802, 2012. http://dx.doi.org/10.1038/ncomms1804

Mark GE, Taylor JM, Broni B, Krug RM, J. Virol. 29, 744-752, 1979.

Marklund JK, Ye Q, Dong J, Tao YJ, Krug RM, J. Virol. 86, 72927297, 2012. http://dx.doi.org/10.1128/JVI.00014-12

Moeller A, Kirchdoerfer RN, Potter CS, Carragher B, Wilson IA, Science 337, 1631-1634, 2012.

Moore MJ, Proudfoot NJ, Cell 136, 688-700, 2009.

Muramoto Y, Noda T, Kawakami E, Akkina R, Kawaoka Y, J. Virol. 87, 2455-2462, 2012.

Naito T, Momose F, Kawaguchi A, Nagata K, J. Virol. 81, 1339-1349, 2007. http://dx.doi.org/10.1128/JVI.01917-06

Neumann G, Brownlee GG, Fodor E, Kawaoka Y, Curr. Top. Microbiol. Immunol. 283, 121-143, 2004. http://dx.doi. org/10.1007/978-3-662-06099-5 4

Ng AK, Zhang H, Tan K, Li Z, Liu JH, Chan PK, Li SM, Chan WY, Au SW, Joachimiak A, Walz T, Wang JH, Shaw PC, FASEB J. 22, 3638-3647, 2008. http://dx.doi.org/10.1096/ f. $.08-112110$

O`Neill RE, Jaskunas R, Blobel G, Palese P, Moroianu J, J. Biol. Chem. 270, 22701-4, 1995. http://dx.doi.org/10.1074/ jbc.270.39.22701

Obayashi E, Yoshida H, Kawai F, Shibayama N, Kawaguchi A, Nagata K, Tame JR, Park SY, Nature 454, 1127-1131, 2008. http://dx.doi.org/10.1038/nature07225

Palese P, Shaw ML, In Knipe DM, Howley PM (Eds): Fields Virology. Wolters Kluwer and Lippincott Williams \& Wilkins, Philadelphia, pp. 1647-1689, 2007.

Paterson D, Fodor E, PLoS Pathog. 8, e1003019, 2012. http://dx.doi. org/10.1371/journal.ppat.1003019

Perez JT, Varble A, Sachidanandam R, Zlatev I, Manoharan M, GarciaSastre A, tenOever BR, Proc. Natl. Acad. Sci. USA 107, 1152511530, 2010. http://dx.doi.org/10.1073/pnas.1001984107

Perez JT, Zlatev I, Aggarwal S, Subramanian S, Sachidanandam R, Kim B, Manoharan M, Tenoever BR, J. Virol. 86, 1347513485, 2012. http://dx.doi.org/10.1128/JVI.02295-12

Poole E, Elton D, Medcalf L, Digard P, Virology 321, 120-133, 2004. http://dx.doi.org/10.1016/j.virol.2003.12.022

Poon LL, Fodor E, Brownlee GG, J. Virol. 74, 418-427, 2000. http:// dx.doi.org/10.1128/JVI.74.1.418-427.2000

Poon LL, Pritlove DC, Fodor E, Brownlee GG, J. Virol. 73, 34733476, 1999.

Poon LL, Pritlove DC, Sharps J, and Brownlee GG, J. Virol. 72, 8214-8219, 1998.

Pritlove DC, Fodor E, Seong BL, Brownlee GG, J. Gen. Virol. 76 (Pt 9), 2205-2213, 1995. http://dx.doi.org/10.1099/00221317-76-9-2205

Read EK, Digard P, J. Gen. Virol. 91, 1290-301, 2010. http://dx.doi. org/10.1099/vir.0.018564-0 
Resa-Infante P, Gabriel G, Bioessays 35, 23-27, 2012. http://dx.doi. org/10.1002/bies.201200138

Resa-Infante P, Jorba N, Coloma R, Ortin J, RNA Biol. 8, 207-215, 2011.

Robb NC, Fodor E, J. Gen. Virol. 93, 113-118, 2012. http://dx.doi. org/10.1099/vir.0.035485-0

Robb NC, Jackson D, Vreede FT, Fodor E, J. Gen. Virol. 91, 23312340, 2010. http://dx.doi.org/10.1099/vir.0.022004-0

Robb NC, Smith M, Vreede FT, Fodor E, J. Gen. Virol. 90, 13981407, 2009. http://dx.doi.org/10.1099/vir.0.009639-0

Robertson JS, Schubert M, Lazzarini RA, J. Virol. 38, 157-163, 1981.

Shapiro GI, Gurney T, Jr, Krug RM, J. Virol. 61, 764-773, 1987.

Shaw MW, Lamb RA, Virus Res. 1, 455-467, 1984. http://dx.doi. org/10.1016/0168-1702(84)90003-0

Sugiyama K, Obayashi E, Kawaguchi A, Suzuki Y, Tame JR, Nagata K, Park SY, EMBO J. 28, 1803-1811, 2009. http://dx.doi. org/10.1038/emboj.2009.138

Tchatalbachev S, Flick R, Hobom G, RNA 7, 979-989, 2010. http:// dx.doi.org/10.1017/S1355838201002424

Turrell L, Lyall JW, Tiley LS, Fodor E, Vreede FT, Nat. Commun. 4, 1591, 2013.

Umbach JL, Yen HL, Poon LL, Cullen BR, MBio 1, e00204-10, 2010.

Vreede FT, Brownlee GG, J. Virol. 81, 2196-2204, 2007. http:// dx.doi.org/10.1128/JVI.02187-06

Vreede FT, Chan AY, Sharps J, Fodor E, Virology 396, 125-134, 2010. http://dx.doi.org/10.1016/j.virol.2009.10.003
Vreede FT, Fodor E, Virulence 1, 436-439, 2010. http://dx.doi. org/10.4161/viru.1.5.12967

Vreede FT, Gifford H, Brownlee GG, J. Virol. 82, 6902-6910, 2008. http://dx.doi.org/10.1128/JVI.00627-08

Vreede FT, Jung TE, Brownlee GG, J. Virol. 78, 9568-9572, 2004. http://dx.doi.org/10.1128/JVI.78.17.9568-9572.2004

Wakefield L, Brownlee GG, Nucleic Acids Res. 17, 8569-8580, 1989. http://dx.doi.org/10.1093/nar/17.21.8569

Wang W, Cui ZQ, Han H, Zhang ZP, Wei HP, Zhou YF, Chen Z, Zhang XE, Nucleic Acids Res. 36, 4913-4928, 2008. http:// dx.doi.org/10.1093/nar/gkn475

Wise HM, Foeglein A, Sun J, Dalton RM, Patel S, Howard W, Anderson EC, Barclay WS, Digard P, J. Virol. 83, 8021-8031, 2009. http://dx.doi.org/10.1128/JVI.00826-09

Wise HM, Hutchinson EC, Jagger BW, Stuart AD, Kang ZH, Robb N, Schwartzman LM, Kash JC, Fodor E, Firth AE, Gog JR, Taubenberger JK, Digard P, PLoS Pathog. 8, e1002998, 2012. http://dx.doi.org/10.1371/journal.ppat.1002998

Yamanaka K, Ishihama A, Nagata K, J. Biol. Chem. 265, 1115111155, 1990.

Ye Q, Krug RM, Tao YJ, Nature 444, 1078-1082, 2006. http://dx.doi. org/10.1038/nature05379

Yuan P, Bartlam M, Lou Z, Chen S, Zhou J, He X, Lv Z, Ge R, Li X, Deng T, Fodor E, Rao Z, Liu Y, Nature 458, 909-913, 2009. http://dx.doi.org/10.1038/nature07720

Zhang S, Wang J, Wang Q, Toyoda T, J. Biol. Chem. 285, 41194-41201, 2010. http://dx.doi.org/10.1074/jbc.M110.130062 